\title{
PINS Testing and Modification for Explosive Identification
}

E. H. Seabury

A. J. Caffrey

September 2011

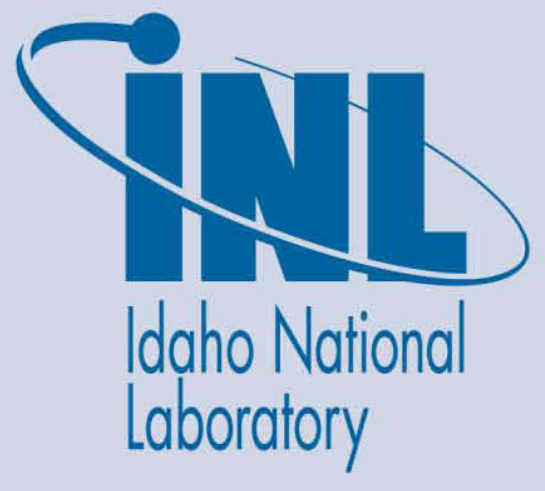

The INL is a U.S. Department of Energy National Laboratory operated by Battelle Energy Alliance 


\section{DISCLAIMER}

This information was prepared as an account of work sponsored by an agency of the U.S. Government. Neither the U.S. Government nor any agency thereof, nor any of their employees, makes any warranty, expressed or implied, or assumes any legal liability or responsibility for the accuracy, completeness, or usefulness, of any information, apparatus, product, or process disclosed, or represents that its use would not infringe privately owned rights. References herein to any specific commercial product, process, or service by trade name, trade mark, manufacturer, or otherwise, does not necessarily constitute or imply its endorsement, recommendation, or favoring by the U.S. Government or any agency thereof. The views and opinions of authors expressed herein do not necessarily state or reflect those of the U.S. Government or any agency thereof. 
INL/EXT-11-23378

\title{
PINS Testing and Modification for Explosives Identification
}

\author{
E. H. Seabury \\ A. J. Caffrey
}

September 2011

\author{
Idaho National Laboratory \\ Idaho Falls, Idaho 83415 \\ http://www.inl.gov
}

Prepared for the

U.S. Department of Energy

Office of National Nuclear Security Administration

Under DOE Idaho Operations Office

Contract DE-AC07-05ID14517 



\begin{abstract}
The INL's Portable Isotopic Neutron Spectroscopy System (PINS) ${ }^{1}$ non-intrusively identifies the chemical fill of munitions and sealed containers. PINS is used routinely by the U.S. Army, the Defense Threat Reduction Agency, and foreign military units to determine the contents of munitions and other containers suspected to contain explosives, smoke-generating chemicals, and chemical warfare agents such as mustard and nerve gas. The objects assayed with PINS range from softball-sized M139 chemical bomblets to 200 gallon DOT 500X ton containers.

INL had previously examined ${ }^{2}$ the feasibility of using a similar system for the identification of explosives, and based on this proof-of-principle test, the development of a dedicated system for the identification of explosives in the presence of special nuclear material for emergency respoders appears entirely feasible. INL has been tasked by NNSA with the development of such a system.
\end{abstract}




\section{CONTENTS}

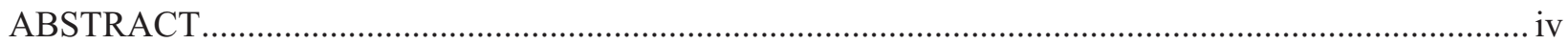

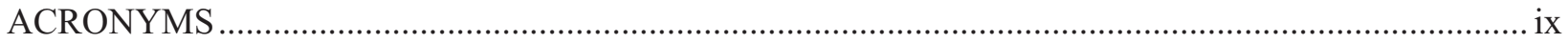

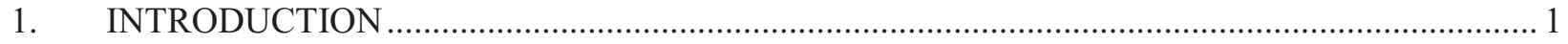

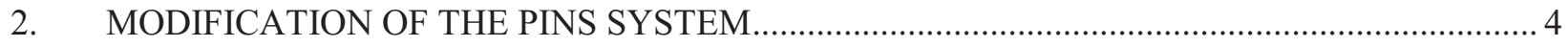

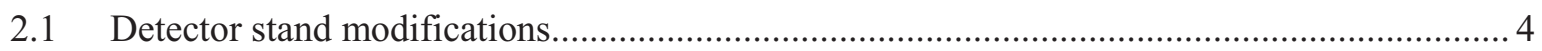

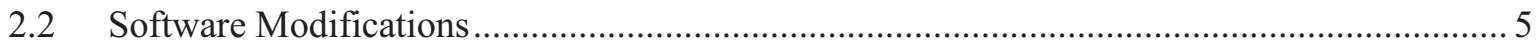

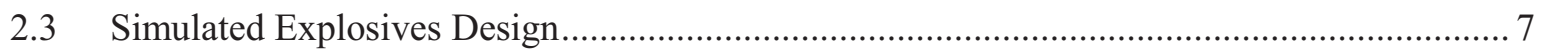

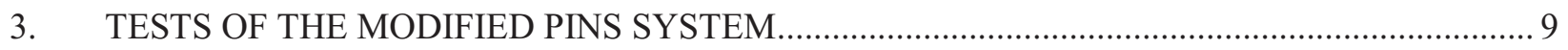

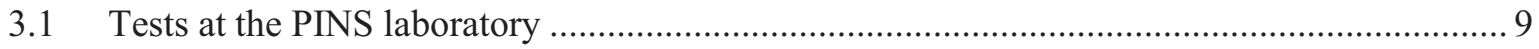

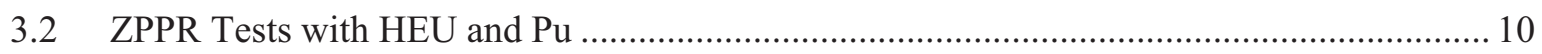

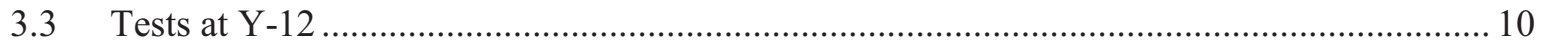

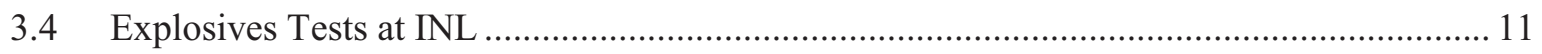

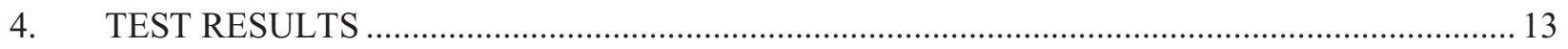

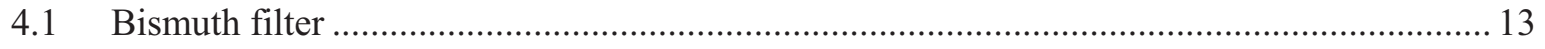

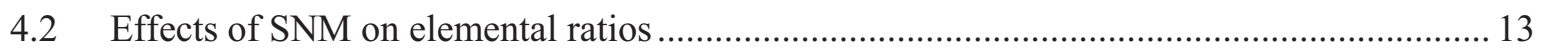

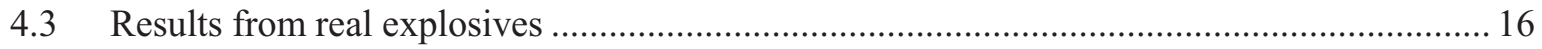

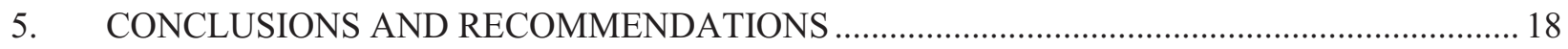

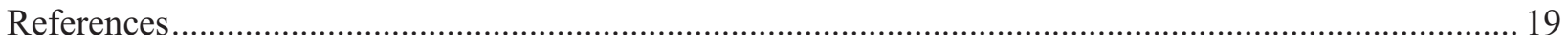

\section{FIGURES}

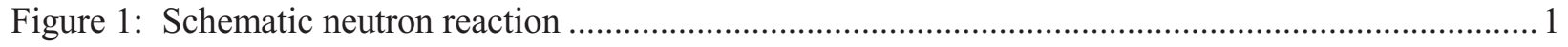

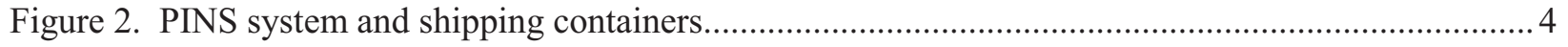

Figure 3. Modified PINS system for explosives identification............................................................... 5

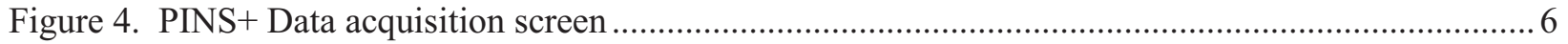

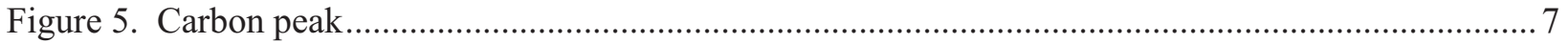

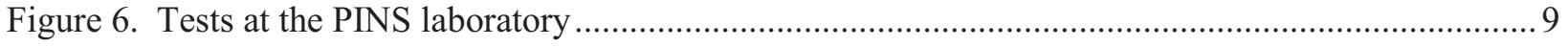

Figure 7. Experimental arrangement for ZPPR tests. The left photo shows the position of the clamshell and the right the final experimental arrangement................................................. 10

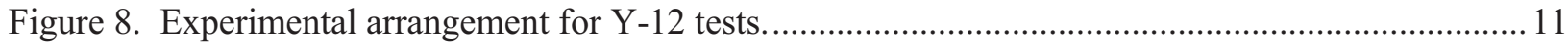

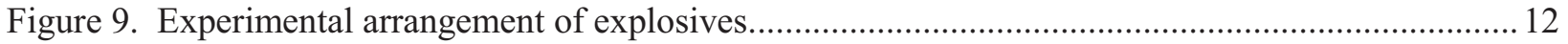

Figure 10. Carbon to hydrogen versus carbon to oxygen ratios for the three simulants.......................... 15

Figure 11. Carbon to nitrogen versus carbon to oxygen ratios for the three simulants. .......................... 15

Figure 12. Oxygen to nitrogen versus carbon to oxygen ratios for the three simulants........................... 16 


\section{TABLES}

Table 1 Elemental composition of explosives in weight percent ${ }^{3}$........................................................ 2

Table 2 Composition of simulated explosives in weight percent ….................................................... 8

Table 3 Comparison of elemental weight ratios of simulants and explosives .......................................... 8

Table 4. Comparison effects of bismuth filter on dead time.................................................................. 13

Table 5. Comparison of elemental ratios measured at the PINS laboratory versus ZPPR....................... 14

Table 6. Elemental ratios from measurements on real explosives ......................................................... 17 


\section{ACRONYMS}

$\begin{array}{ll}\text { DT } & \text { Deuterium tritium } \\ \text { HPGe } & \text { High purity germanium } \\ \text { INL } & \text { Idaho National Laboratory } \\ \text { MCA } & \text { Multi channel analyzer } \\ \text { MCNP } & \text { Monte Carlo n-particle } \\ \text { NDSTC } & \text { Nuclear Detection and Sensor Testing Center } \\ \text { NNSA } & \text { National Nuclear Security Administration } \\ \text { PINS } & \text { Portable Isotopic Neutron Spectroscopy } \\ \text { SNM } & \text { Special nuclear material } \\ \text { ZPPR } & \text { Zero Power Physics Reactor }\end{array}$




\section{PINS Testing and Modifications for Explosives Identification}

\section{INTRODUCTION}

PINS employs neutron radiation to probe the chemical elements within a container without the need to open or even touch the container. A radioisotopic neutron source or an electronic neutron generator shines neutrons on the item under test. The neutrons, in turn, penetrate the container or munition where they interact with the atomic nuclei of the filler material, producing gamma rays characteristic of the chemical elements inside the item. These energetic gamma rays can penetrate even the thick steel wall of an artillery projectile to escape and trigger a gamma-ray spectrometer.

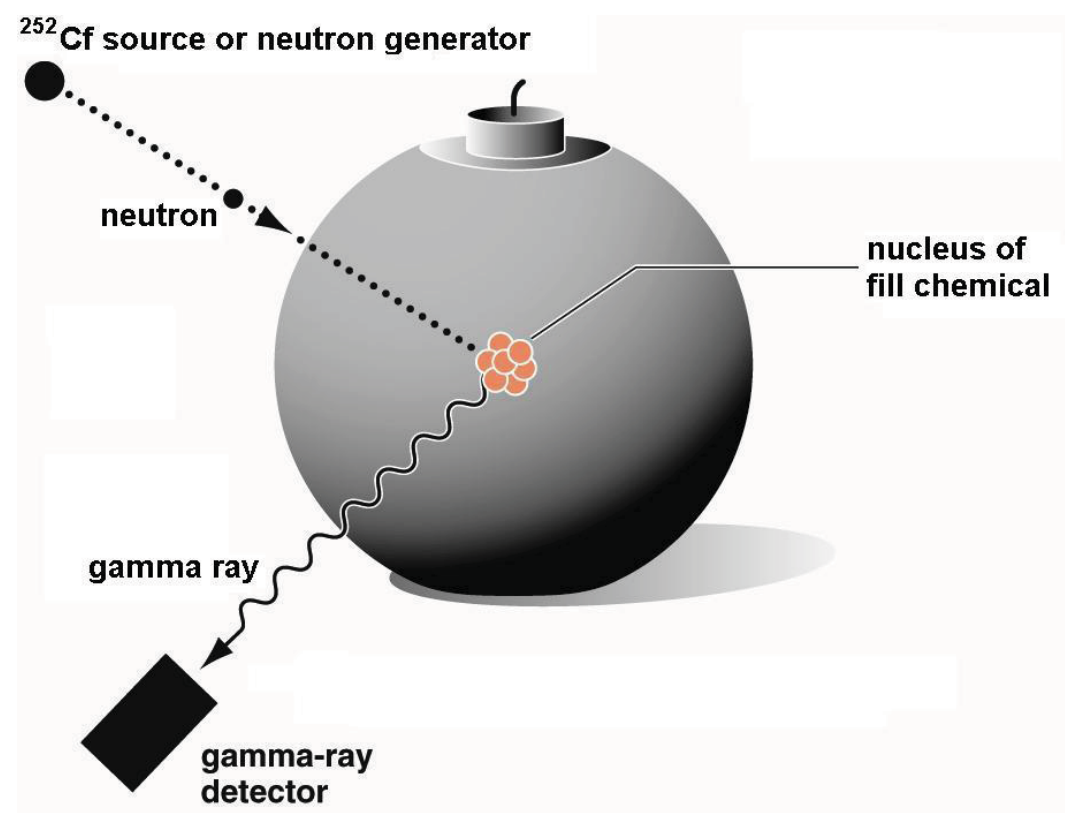

Figure 1: Schematic neutron reaction

This technique is called Prompt Gamma-ray Neutron Activation Analysis (PGNAA). A schematic neutron reaction event is shown above in Figure 1. The energies and intensities of these gamma rays, as measured by the spectrometer, identify the elemental composition of the fill material. 
Table 1 Elemental composition of explosives in weight percent ${ }^{3}$

\begin{tabular}{|l|r|r|r|r|r|r|r|r|r|r|r|}
\hline & HMX & LX-17 & TNT & COMPB & TATB & PBX-9501 & PBX-9502 & PETN & ANFO & Black Powder & TATP \\
\hline H & 2.7 & 2.2 & 2.2 & 2.7 & 2.3 & 2.9 & 2.2 & 2.55 & 5.4 & & 8.2 \\
\hline C & 16.2 & 27.5 & 37.0 & 24.3 & 27.9 & 17.7 & 27.6 & 19.0 & 2.6 & 9.3 & 48.6 \\
\hline $\mathbf{O}$ & 43.2 & 34.4 & 42.3 & 42.6 & 37.2 & 43.0 & 35.3 & 60.7 & 58.1 & 35.2 & 43.2 \\
\hline N & 37.8 & 30.1 & 18.5 & 30.4 & 32.6 & 36.4 & 31.0 & 17.7 & 33.9 & 10.3 & \\
\hline CI & & 1.9 & & & & & 1.3 & & & & \\
\hline F & & 2.2 & & & & & 1.4 & & & & \\
\hline S & & & & & & & & & & 16.5 & \\
\hline K & & & & & & & & & & & 28.7 \\
\hline
\end{tabular}

Chemical Warfare Materiel (CWM), e.g. nerve agent GB, is relatively simple to identify based on its gamma-ray signature, due to the variety of chemical elements in the different chemicals. Explosives, however, are somewhat more difficult to distinguish from one another as they are largely comprised of the same four elements: carbon, hydrogen, nitrogen, and oxygen. Table 1 shows the elemental composition $^{3}$ of some explosives of interest. As can be seen in the table, some plastic-bonded explosives contain the elements chlorine and fluorine, but the bulk of the material is still carbon, oxygen, hydrogen, and nitrogen.

Our previous work comprised studying the response of a gamma spectrometer to neutron-induced gamma rays from kilogram or larger masses of the explosives listed in Table 1 both in Monte Carlo simulations as well as a limited set of experiments. The conclusion from these studies was that using a deuterium-tritium (DT) neutron generator provided the best excitation of carbon and oxygen in the explosives and that the calculation of elemental ratios provided some discrimination of different explosive types.

Figure 2 below shows a plot of hydrogen-to-nitrogen and carbon-to-oxygen elemental ratios from MCNP calculations using $5 \mathrm{~kg}, 10 \mathrm{~kg}$, and $15 \mathrm{~kg}$ masses of the various explosives. The hydrogen to nitrogen ratio was based on gamma-rays from thermal neutron capture whereas the carbon to oxygen ratio was based on gamma rays from neutron inelastic scattering. Using gamma rays from neutron interactions based on similar neutron energies removes most of the effects from the shape of the explosives. As can be seen in the Figure, use of these elemental ratios provides a good degree of separations of the different explosive types. Areas where explosives overlap are largely due to explosives being based on the same type, e.g. PBX-9502 and LX-17 are both TATB-based plastic-bonded explosives. 


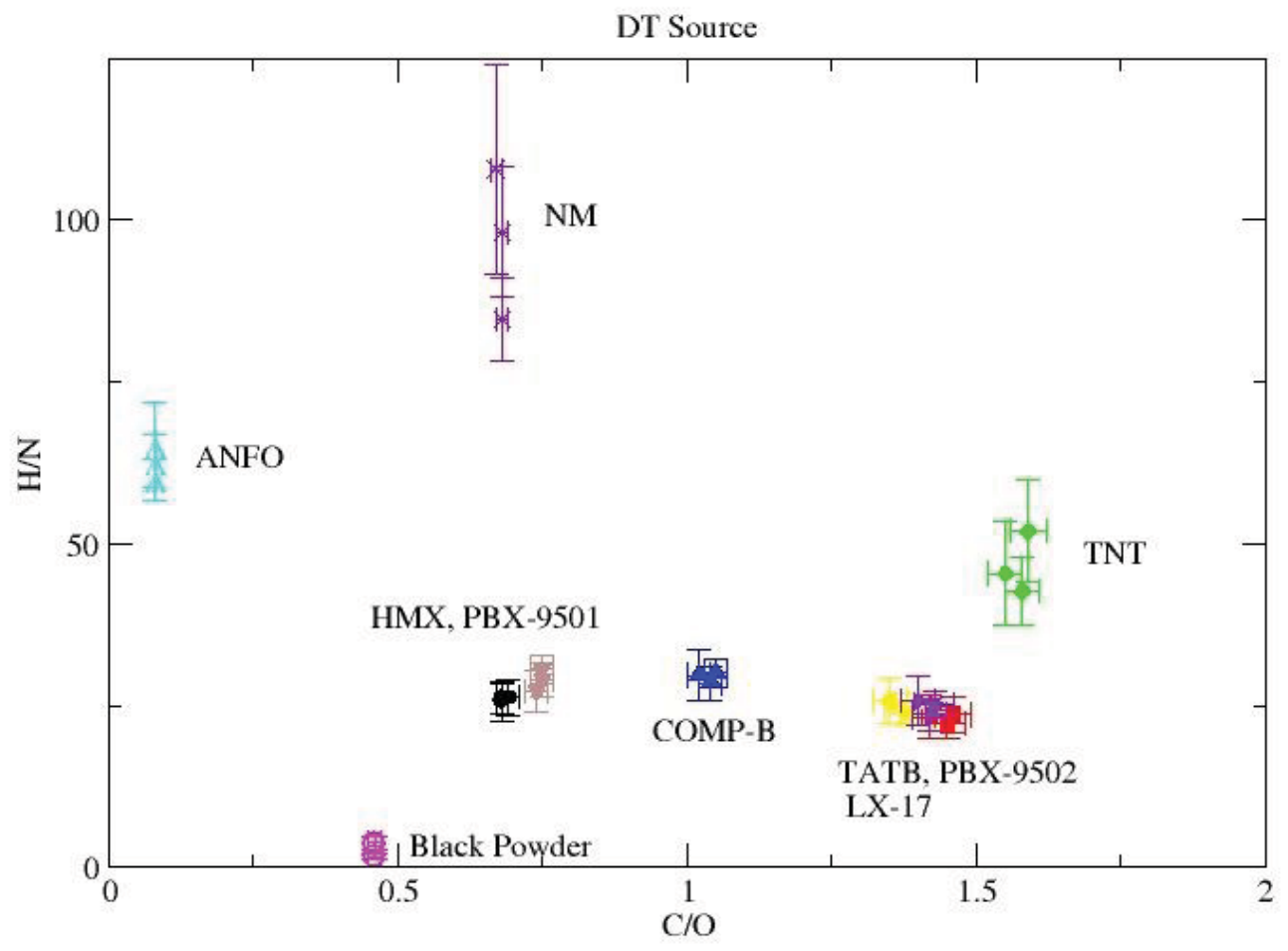

Figure 1 Elemental ratios for explosives 


\section{MODIFICATION OF THE PINS SYSTEM}

The PINS system as it is currently deployed by the U.S. Army and others uses a ${ }^{252} \mathrm{Cf}$ isotopic neutron source to excite gamma rays within the object under assessment. In order to identify explosives, the PINS system had to be modified to use a DT electronic neutron generator, have the detector stand modified to support the generator and detector, and have the data acquisition and analysis software changed for this application.

\subsection{Detector stand modifications}

The current PINS detector stand holds the HPGe detector, tungsten shielding blocks, as well as a polyethylene moderator and source holder. This stand would not easily be adapted to holding a portable neutron generator and the larger amount of shielding that would be necessary for the explosives identification application. We therefore designed a new stand, a photo of which can be seen in Figure 2 .

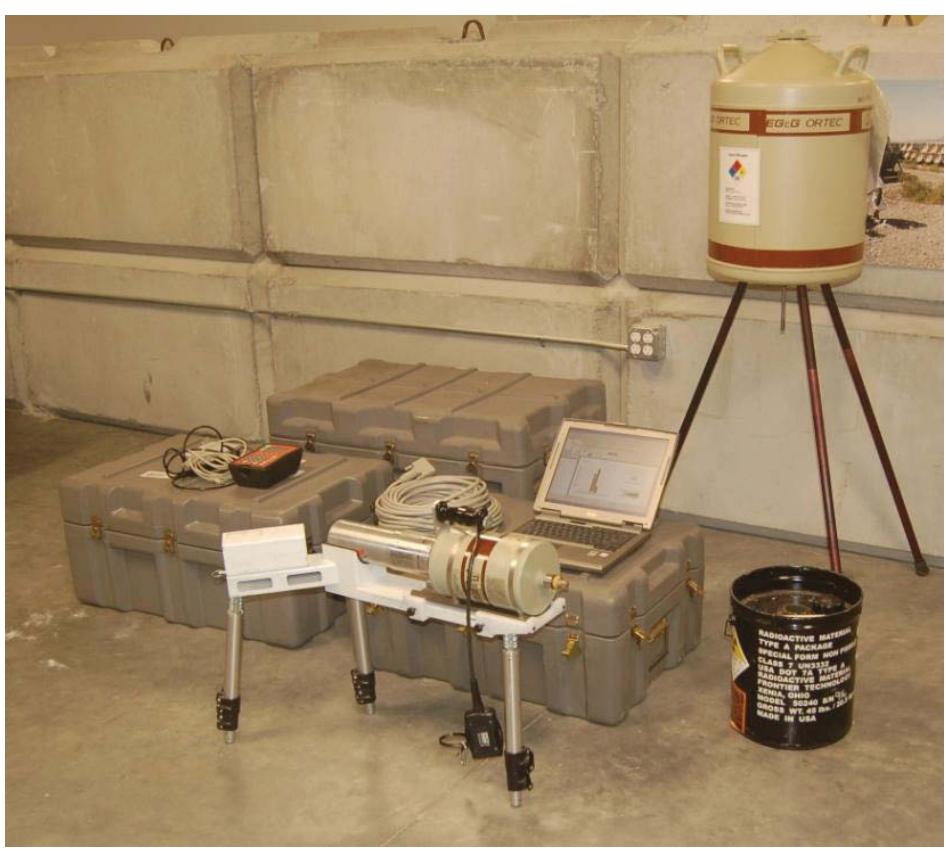

Figure 2. PINS system and shipping containers 


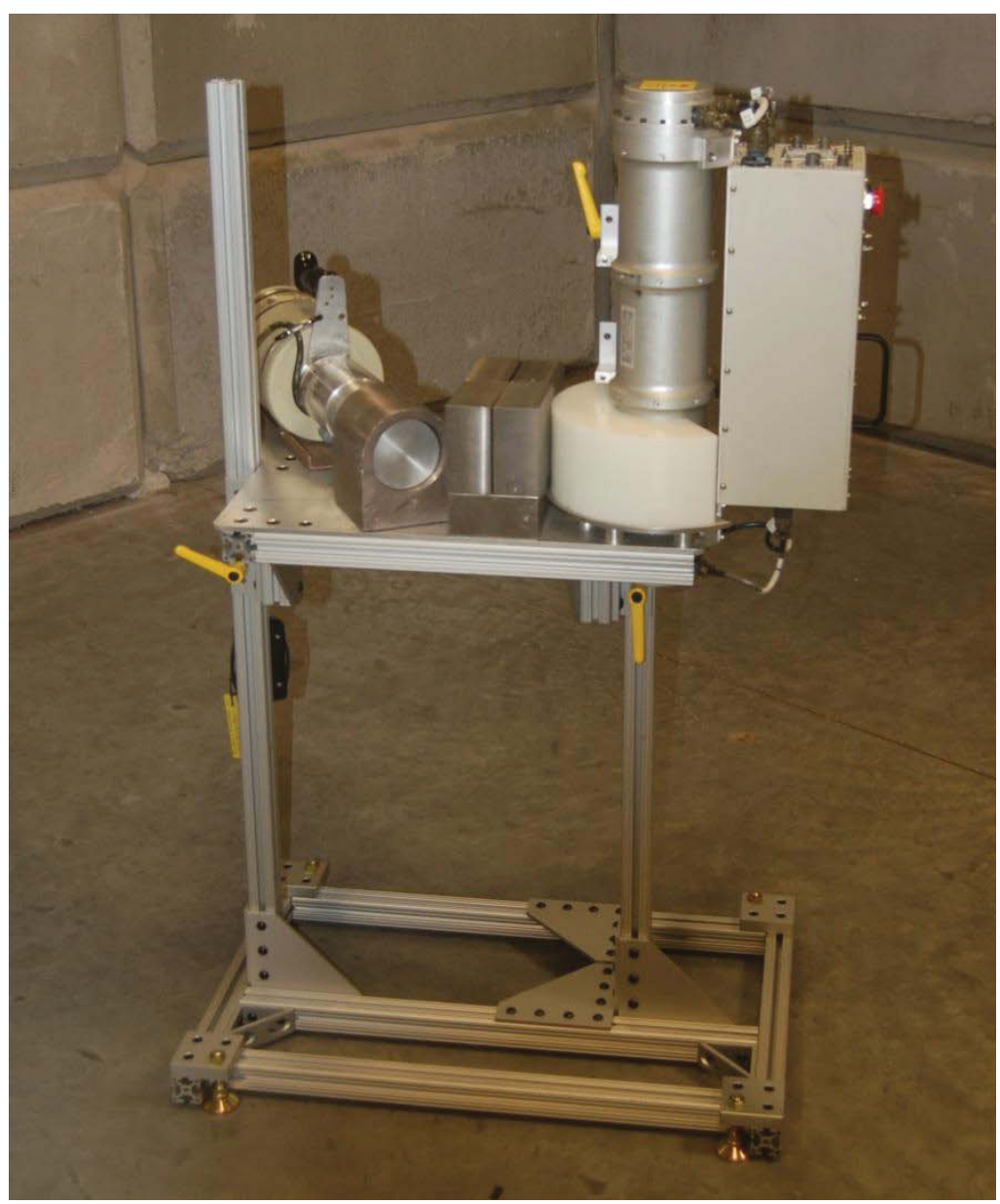

Figure 3. Modified PINS system for explosives identification

The modified PINS stand supports the HPGe detector, bismuth collimator, tungsten shadow shield, polyethylene moderator, and neutron generator. The polyethylene moderator is necessary to excite some gamma rays from thermal neutron capture in the object under assessment. The view by the detector of this polyethylene and the neutron generator target is shielded by the tungsten blocks. The bismuth collimator shields the detector from gamma rays generated in the tungsten as well as some $\mathrm{x}$ rays produced by the neutron generator itself. The detector is a standard PINS detector, cooled by liquid nitrogen, with a relative efficiency of approximately $45 \%$.

\subsection{Software Modifications}

The PINS system data acquisition and control software is called PINS+. This program is generally run on a notebook computer that communicates via USB with a DigiDart MCA produced by Ortec. The neutron generator is generally controlled over an RS/232 link with the notebook computer as well. This software was designed to identify chemical warfare materiel in munitions, but some of this same functionality could be adapted to the identification of explosives. A screen shot of the software in data acquisition mode can be seen in Figure 4. 


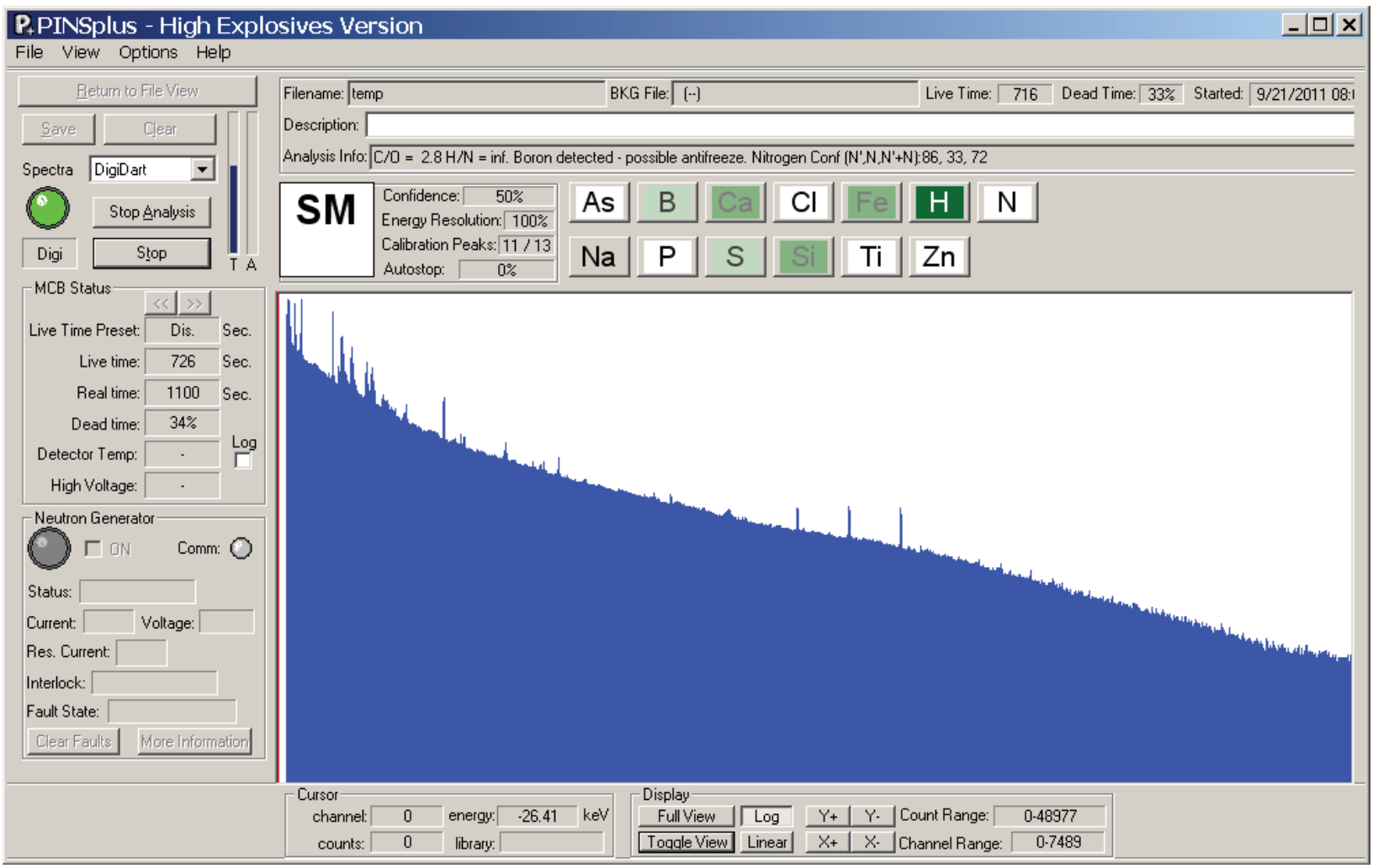

Figure 4. PINS+ Data acquisition screen

This software already had all of the detector and neutron generator control built in before the start of the modifications. The major changes were in the fill identification algorithms that allow the detection of explosives and identification of chemical warfare materiel. The standard system automatically performs peak-fitting of the gamma spectrum and uses the peak areas obtained in a fill-identification algorithm that provides a confidence that the assessed item is consistent with a known fill in its library. For example, if chlorine and sulfur were detected by the standard software, a ratio of the peak areas would be obtained and it would be determined whether the ratio was consistent with mustard gas or some other chemical. In the case of explosives identification, only four elements are used: carbon, oxygen, hydrogen, and nitrogen.

The adapted PINS+ software measures the carbon peak area by summing the area under the broad $4439 \mathrm{keV}$ peak caused by neutron inelastic scattering. A plot of this peak is shown in Figure 5 below where one can also see a much narrower peak from oxygen excitation. This spectrum was obtained from a measurement of simulated TNT. Other peaks from nitrogen, hydrogen, and oxygen are fit automatically by the software and peak areas are obtained. 


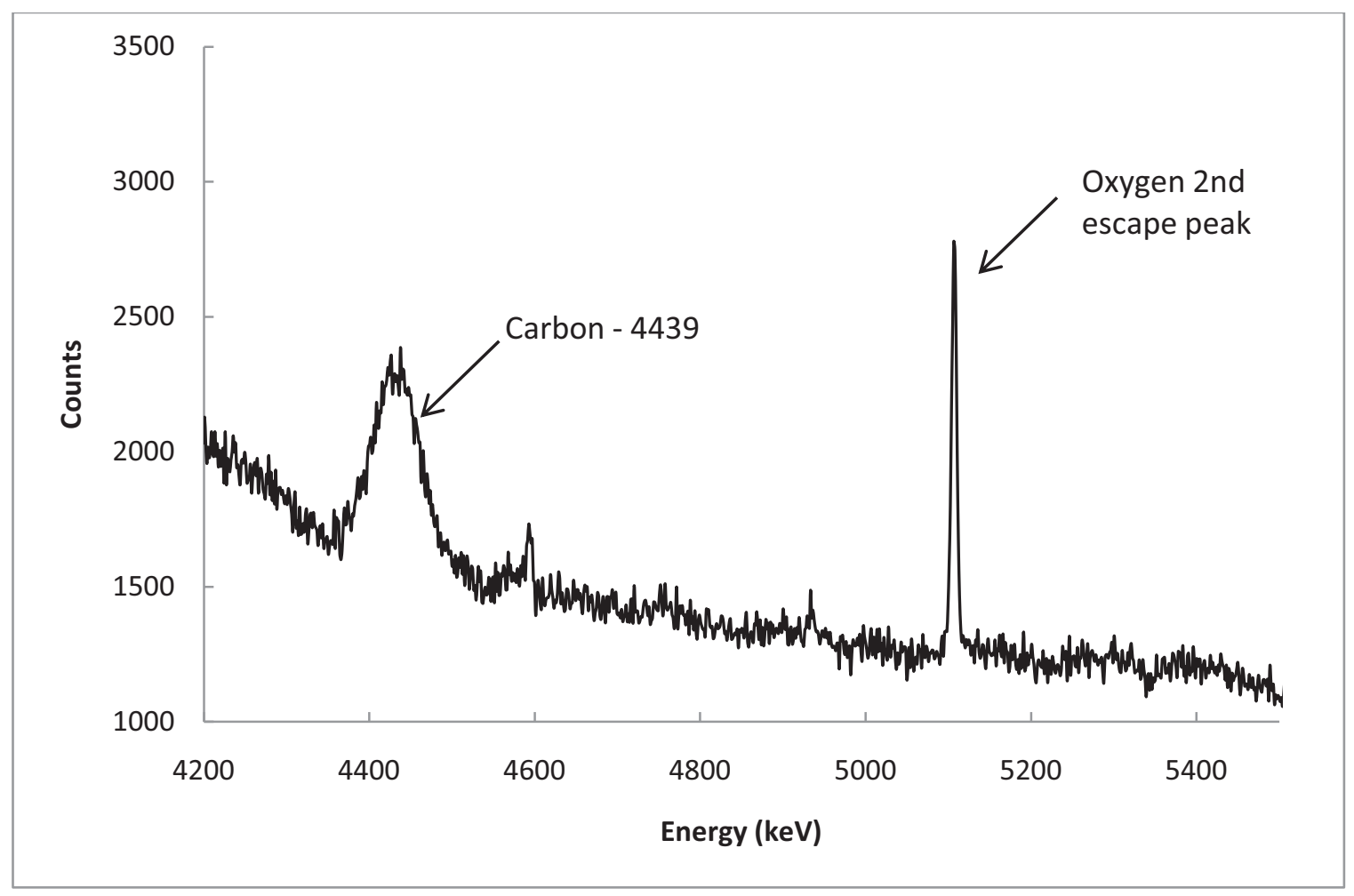

Figure 5. Carbon peak

The determination of the explosive type is made by examining ratios of different peak areas. Currently three explosives are identified by the software, TNT, TATB, HMX, and Comp. B. All of the logic containing identification of chemical warfare materiel has been removed from the program and only explosives will be identified in the new version. The determination of what elemental ratios to use in the software was determined by measurements on both simulated and real explosives, both in the presence of SNM and with no SNM present.

\subsection{Simulated Explosives Design}

In order to test the PINS system in the presence of SNM simulated explosives or simulants had to be designed. Real explosives are not allowed at any of the facilities where we had access to SNM in the form of fuel components or weapon components. The main goal in the design of the simulants was to achieve the same elemental ratios, e.g. carbon to oxygen, while maintaining the same neutronic behavior of the simulant to the DT generator used in the system, and to use innocuous components. The key to maintaining the same neutronic behavior is by maintaining the same hydrogen content in the simulant as the real explosive. The simulants we designed are shown in Table 2 below. A comparison of the elemental ratios of the simulants versus the real explosives is shown in Table 3.

As can be seen in the two tables below, the simulants have very good agreement with the explosives in their carbon to oxygen ratios. This ratio is key to discriminating the various explosive types as was shown in the MCNP calculations and previous measurements. Similarly the hydrogen to nitrogen ratios are in good agreement with the exception of the HMX simulant. The HMX simulant has a ratio more like that of TATB than of real HMX. 
Table 2 Composition of simulated explosives in weight percent

\begin{tabular}{|l|c|c|c|}
\hline Component & HMX -sim & TNT-sim & TATB-sim \\
\hline Melamine & $25 \%$ & $25 \%$ & $50 \%$ \\
\hline Graphite & & $15 \%$ & \\
\hline Ammonium Bicarbonate & $10 \%$ & $15 \%$ & \\
\hline Sodium Bicarbonate & $65 \%$ & $45 \%$ & $50 \%$ \\
\hline
\end{tabular}

Table 3 Comparison of elemental weight ratios of simulants and explosives

\begin{tabular}{|l|c|c|c|c|c|}
\hline Explosive & $\mathbf{C / O}$ & $\mathbf{C} / \mathbf{N}$ & $\mathbf{C} / \mathbf{H}$ & $\mathbf{H} / \mathbf{N}$ & $\mathbf{O} / \mathbf{N}$ \\
\hline TATB-sim & 0.75 & 0.64 & 7.12 & 0.072 & 0.85 \\
\hline TATB & 0.75 & 0.86 & 11.91 & 0.090 & 1.25 \\
\hline HMX-sim & 0.41 & 0.97 & 5.96 & 0.072 & 2.37 \\
\hline HMX & 0.38 & 0.43 & 6.83 & 0.142 & 1.13 \\
\hline TNT-sim & 0.89 & 1.67 & 12.65 & 0.13 & 1.88 \\
\hline TNT & 0.88 & 2.00 & 16.68 & 0.12 & 2.27 \\
\hline PETN & 0.31 & 1.07 & 7.45 & 0.14 & 3.43 \\
\hline
\end{tabular}




\section{TESTS OF THE MODIFIED PINS SYSTEM}

In order to test the performance of the system and modify some design parameters, the modified PINS system was tested using simulated explosives at INL's PINS laboratory, INL's ZPPR facility where SNM was available, Y-12's Nuclear Detection and Sensor Testing Center on weapon components, and finally at INL's Critical Infrastructure Test Range where live explosives could be used for testing. Details of the testing at each facility are given below.

\subsection{Tests at the PINS laboratory}

Measurements at INL's PINS laboratory were performed to assess the performance of the detector/neutron generator stand design before the final fabrication as well as to assess the response of the simulated explosives. A photo of a typical experimental arrangement can be found in Figure 6 below.

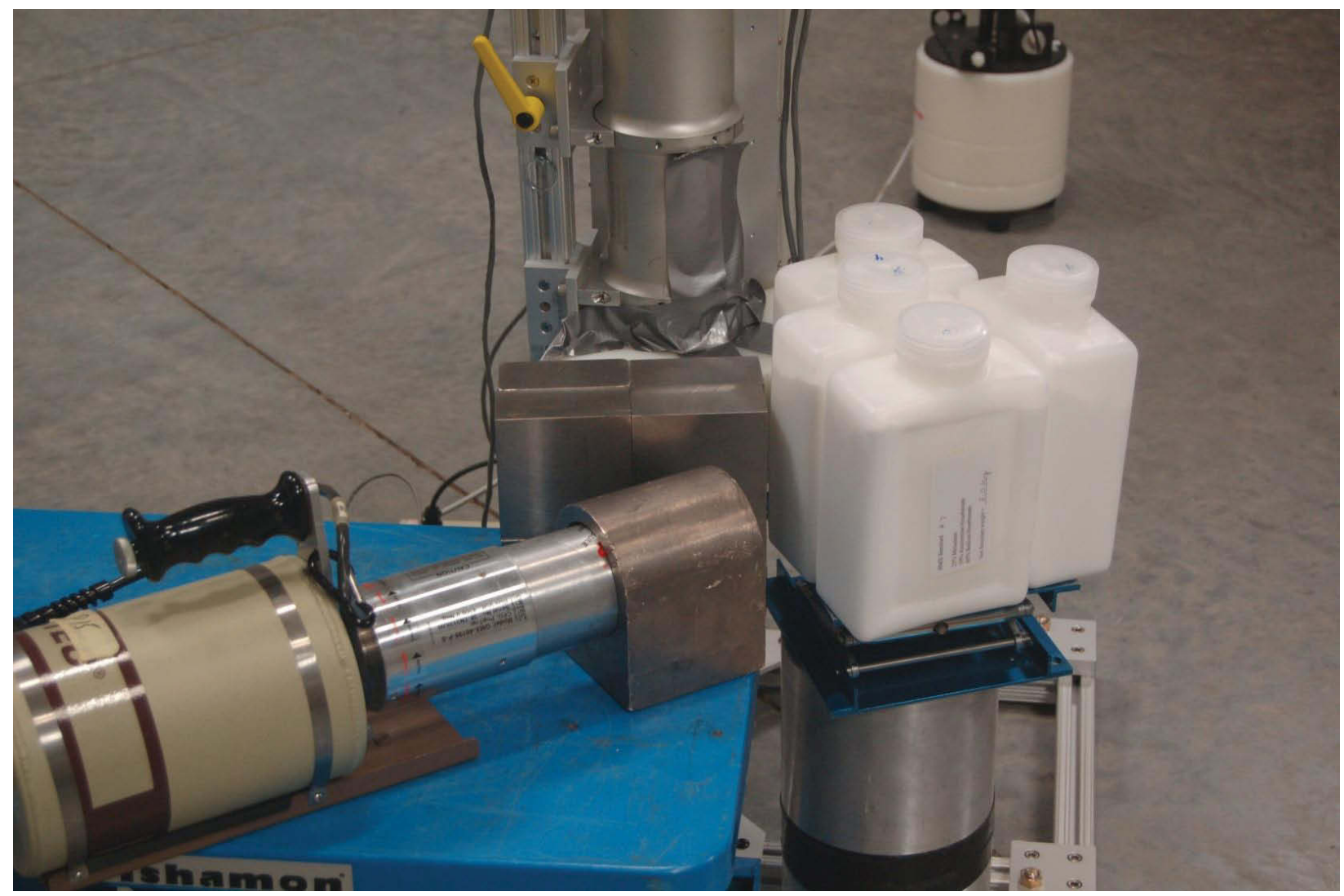

Figure 6. Tests at the PINS laboratory

Measurements were performed on bare simulants without any SNM present. The detector shielding and neutron generator moderator configurations used were the same as would be in the new modified detector/generator stand. These initial measurements were also used to characterize the elemental area ratios that would be used in the PINS+ software to identify explosives. 


\subsection{ZPPR Tests with HEU and Pu}

One of the key tests of the modified PINS system was at INL's ZPPR facility. The facility allows the use of $\mathrm{kg}$ quantities of highly-enriched uranium as well as ${ }^{239} \mathrm{Pu}$. These materials were in the form of metal fuel plates, approximately 2 -inches by 4 -inches by $1 / 8$ inch. An array of these plates is placed in a storage container, called a "clamshell", which can in turn be placed in the desired experimental configuration. Figure 7 below shows the positioning of the clamshell for the ZPPR tests.
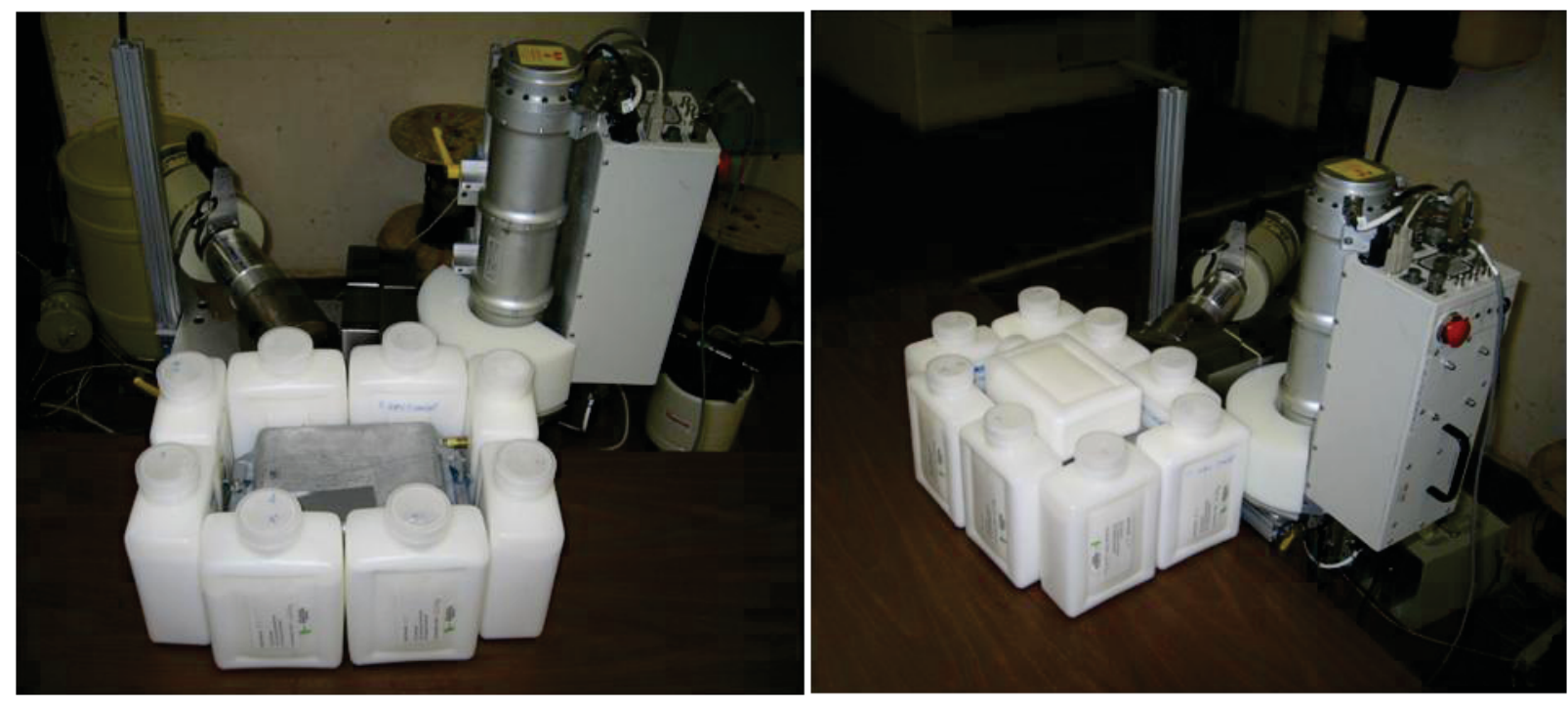

Figure 7. Experimental arrangement for ZPPR tests. The left photo shows the position of the clamshell and the right the final experimental arrangement.

Two different clamshells were used in the ZPPR tests. The first contained $9.1 \mathrm{~kg}$ of $94 \%$ enriched HEU, the second contained $1.9 \mathrm{~kg}$ of $\mathrm{Pu}, 91 \%$ of which was ${ }^{239} \mathrm{Pu}$. The simulated explosives were contained in 2-liter rectangular nalgene bottles to allow convenient stacking and placement of the simulants. A bottle was placed on a table and the clamshell was placed on top of the bottle. The clamshell was then surrounded by simulant bottles with one final bottle being placed on top of the clamshell as can be seen in the right photo of Figure 7.

One of the key questions to be answered was the effect of the radioactivity of the SNM itself on the performance of the HPGe detector. PINS is normally used to assess items that are not themselves radioactive and the shielding around the detector is designed accordingly. The radioactivity of the SNM, if high enough, could cause the detector and associated data acquisition electronics to be busy and affect the performance of the system. To mitigate the effects of this "dead time", bismuth filters of varying thicknesses were tested. The bismuth filters attenuate low energy gamma and $\mathrm{x}$ rays greatly and higher energy gamma rays to a lesser extent. Both $\mathrm{HEU}$ and $\mathrm{Pu}$ emit primarily low energy gamma rays.

\subsection{Tests at $\mathrm{Y}-12$}

The measurements performed at Y-12's Nuclear Detection and Sensor Testing Center were used to test the performance of the modified PINS system in the presence of HEU test objects with shapes unique to their facility. Three test objects were used with all three simulated explosives. The first test object, an HEU casting contained $17.9 \mathrm{~kg}$ of $93 \%$ enriched HEU. This casting was in a can. A photo of a similar can arranged with the simulated explosives at Y-12 can be seen in Figure 8. The can in the photo is empty. 
Measurements on the HEU casting were performed as in the photo of Figure 8. The two other test objects were of classified shapes. The simulated explosives, like in the ZPPR tests, were arranged to surround the test objects including the top and bottoms of the test objects. All measurements performed at Y-12 were made using the blue colored steel table as a support for the test objects and the simulants.

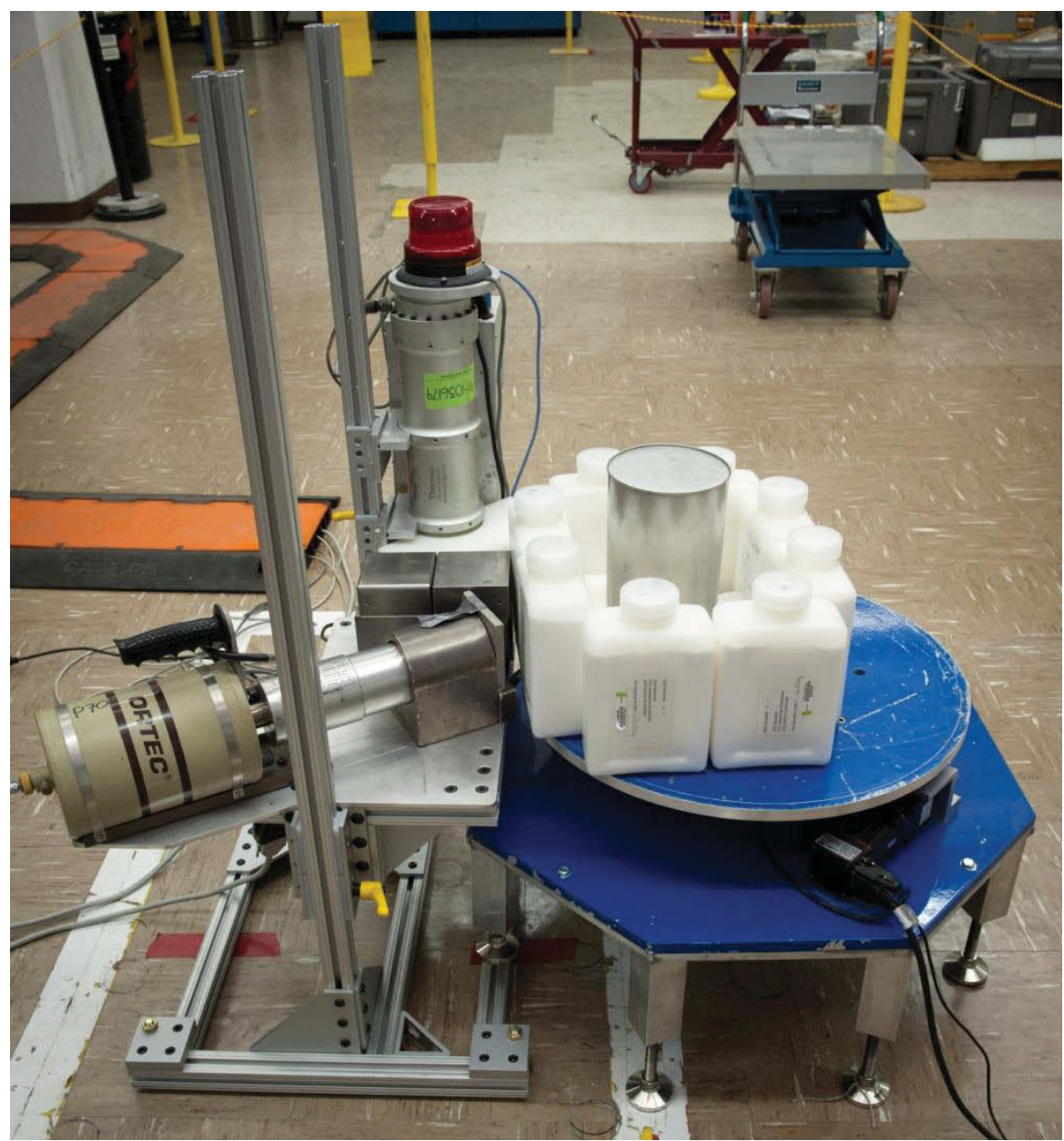

Figure 8. Experimental arrangement for $\mathrm{Y}-12$ tests.

\subsection{Explosives Tests at INL}

Measurements using the modified PINS system were performed at INL's Critical Infrastructure Test Range on live explosives. The explosives used were 25-1bs C-4, one Composition B shaped charge, 36 pounds of PETN-based booster charges, and finally a spool of PETN-based detonation cord. A photo of the C-4 arrangement can be seen in Figure 8 below. C-4 is an RDX-based explosive with the same elemental ratios as HMX. The explosives were kept in their packing containers, but positioned such that the bulk of the explosive was aligned near the front face of the detector and the neutron generator target plane. The stacks of C-4 sticks shown in Figure 9 are an example of the positioning of the explosives within their packing containers. 


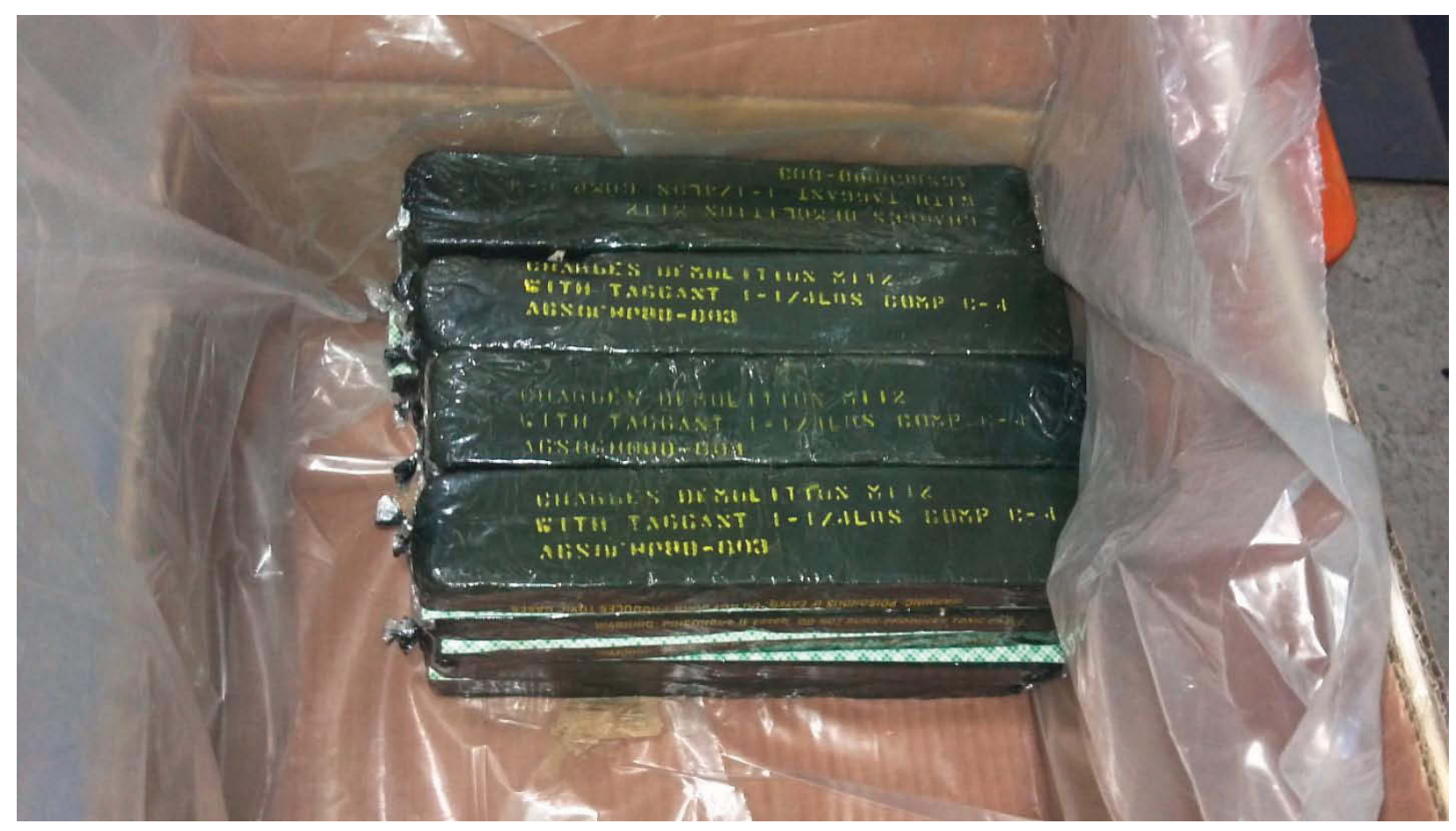

Figure 9. Experimental arrangement of explosives. 


\section{TEST RESULTS}

The following sections described the results of the tests of the bismuth filter measurements, the effects of SNM on the elemental ratios, and a comparison of simulant measurements with those on live explosives.

\subsection{Bismuth filter}

Tests to determine the necessary thickness of bismuth shielding to prevent excessive dead time on the data acquisition electronics were performed at ZPPR. The ${ }^{239} \mathrm{Pu}$ clamshell was placed at detector height in front of the system and a bottle of simulant was placed between the clamshell and the detector face. Varying thicknesses of bismuth were placed in front of the detector face to determine the optimum thickness for the system. The bismuth thicknesses and detector dead time percentages can be seen in Table 5 below. No neutron sources were used during the measurements of the detector dead time, the only activity being measured was from the SNM itself.

With no bismuth filter and the simulant bottle between the detector and the Pu clamshell, the data acquisition electronics were almost completely dead. Putting a $1 / 8$ inch sheet of bismuth in front of the bare face of the detector reduced the dead time significantly, from $99.9 \%$ to $21.1 \%$. Previous measurements with the neutron generator allowed us to expect approximately $20-25 \%$ dead time during a background measurement with no test object in front of the system. Because the PINS system generally operates best with a dead time below $40 \%$, we opted for a $3 / 8$ inch thickness of bismuth in front of the detector face for general measurements. This thickness allows for dead time from the neutron generator as well as the inherent activity from the SNM present in the test object.

Table 4. Comparison effects of bismuth filter on dead time

\begin{tabular}{|l|l|l|l|l|l|l|l|l|l|l|}
\hline $\begin{array}{l}\text { Thickness } \\
\text { (inches) }\end{array}$ & 0 & $1 / 8$ & $1 / 4$ & $3 / 8$ & $1 / 2$ & $5 / 8$ & $3 / 4$ & 1 & 1.5 & 2.0 \\
\hline $\begin{array}{l}\text { Dead } \\
\text { Time }\end{array}$ & $99.9 \%$ & $21.1 \%$ & $15.3 \%$ & $12.5 \%$ & $11.0 \%$ & $10.4 \%$ & $9.9 \%$ & $9.1 \%$ & $8.5 \%$ & $8.4 \%$ \\
\hline
\end{tabular}

Although no bismuth filter was necessary for the HEU measurements performed at ZPPR, when measurements were performed at NDSTC it was found that the dead time produced by the test objects, including the HEU casting, produced an unacceptably high dead time in the system. The HEU casting is a cylindrical shell with a hollow center. With the casting surrounded by simulated TNT, it was found that the dead time was $42 \%$ without the neutron generator operating. Our measurements at ZPPR on HEU plates had much lower dead times, typically on the order of a few percent. This is due to the selfshielding produced by the detector only having had a direct view of the front two fuel plates with the remaining fuel plates each being shielded by the ones in front of them. Measurements on test objects with a larger surface area of the HEU viewable by the detector than that of the ZPPR fuel plates, approximately 2 -inches by 8 inches, will also need the bismuth filter in place to reduce dead time.

\subsection{Effects of SNM on elemental ratios}

One of the items to be determined was the effect, if any, the presence of SNM had on the response of the PINS system to the simulated explosives. Table 4 below shows a comparison of the peak area ratios of simulant measurements performed at the PINS laboratory where no SNM was present and those performed at the ZPPR and NDSTC facilities where kg quantities of either HEU or Pu were present. The uncertainties given in the table are the standard deviation of the ratio measured at that location. 
Table 5. Comparison of elemental ratios measured at the PINS laboratory versus ZPPR

\begin{tabular}{|l|l|l|l|}
\hline & PINS Laboratory & ZPPR & NDSTC \\
\hline HMX-Sim C/O & $2.5 \pm 0.03$ & $2.2 \pm 0.4$ & $2.7 \pm 0.4$ \\
\hline HMX-Sim C/N & $10 \pm 5.5$ & $6.4 \pm 1.7$ & $20 \pm 3.7$ \\
\hline HMX-Sim C/H & $1.0 \pm 0.07$ & $0.55 \pm 0.03$ & $0.65 \pm 0.13$ \\
\hline HMX-Sim O/N & $4.0 \pm 2.2$ & $2.9 \pm 0.21$ & $4.0 \pm 2.4$ \\
\hline TNT-Sim C/O & $4.4 \pm 0.13$ & $4.6 \pm 0.31$ & $3.8 \pm 0.45$ \\
\hline TNT-Sim C/N & $19 \pm 1.5$ & $9.4 \pm 0.22$ & $17 \pm 4.1$ \\
\hline TNT-Sim C/H & $1.7 \pm 0.21$ & $0.91 \pm 0.02$ & $1.0 \pm 0.16$ \\
\hline TNT-Sim O/N & $4.3 \pm 0.47$ & $2.0 \pm 0.10$ & $2.5 \pm 1.5$ \\
\hline TATB-Sim C/O & $4.5 \pm 0.11$ & $5.97 \pm 0.21$ & $3.6 \pm 0.41$ \\
\hline TATB-Sim C/N & $7.2 \pm 0.98$ & $4.8 \pm 0.58$ & $10 \pm 3.5$ \\
\hline TATB-Sim C/H & $1.1 \pm 0.07$ & $0.75 \pm 0 . .02$ & $0.60 \pm 0.07$ \\
\hline TATB-Sim O/N & $1.6 \pm 0.26$ & $0.80 \pm 0.07$ & $1.1 \pm 0.44$ \\
\hline
\end{tabular}

The table shows that the elemental ratios are not greatly affected by the presence of SNM. Assuming that the elemental ratios measured at the PINS laboratory without any SNM present are the standard, one would expect a consistent change in a ratio measured at both ZPPR and NDSTC if SNM had a significant effect on the ratio. This does not appear to be the case. For example the C/O ratio measured at ZPPR for HMX simulant is lower than that measured at the PINS laboratory whereas the same ratio measured at NDSTC has a higher value than that of the PINS laboratory.

There are some ratios with large standard deviations, in particular those that involve the nitrogen peak area. This is due to this peak's relative weakness. In addition to some ratios having large standard deviations, there are also some where the measurements performed at one location do not overlap those performed at another. This would be expected for the $\mathrm{C} / \mathrm{H}$ ratio where the carbon peak is excited through inelastic neutron scattering and the hydrogen peak through thermal neutron capture and the ratio is therefore affected by differences in the geometries of the two measurements. In the case of the ratios involving nitrogen, the differences are likely due to the weakness of the nitrogen peak.

In order to discriminate explosives from one another the elemental ratios not only have to agree between sets of measurements, but must also distinguish one explosive from another. Figures 10 through 12 below show plots of the elemental ratios to help visualize discrimination among the three simulants used in the measurements. 


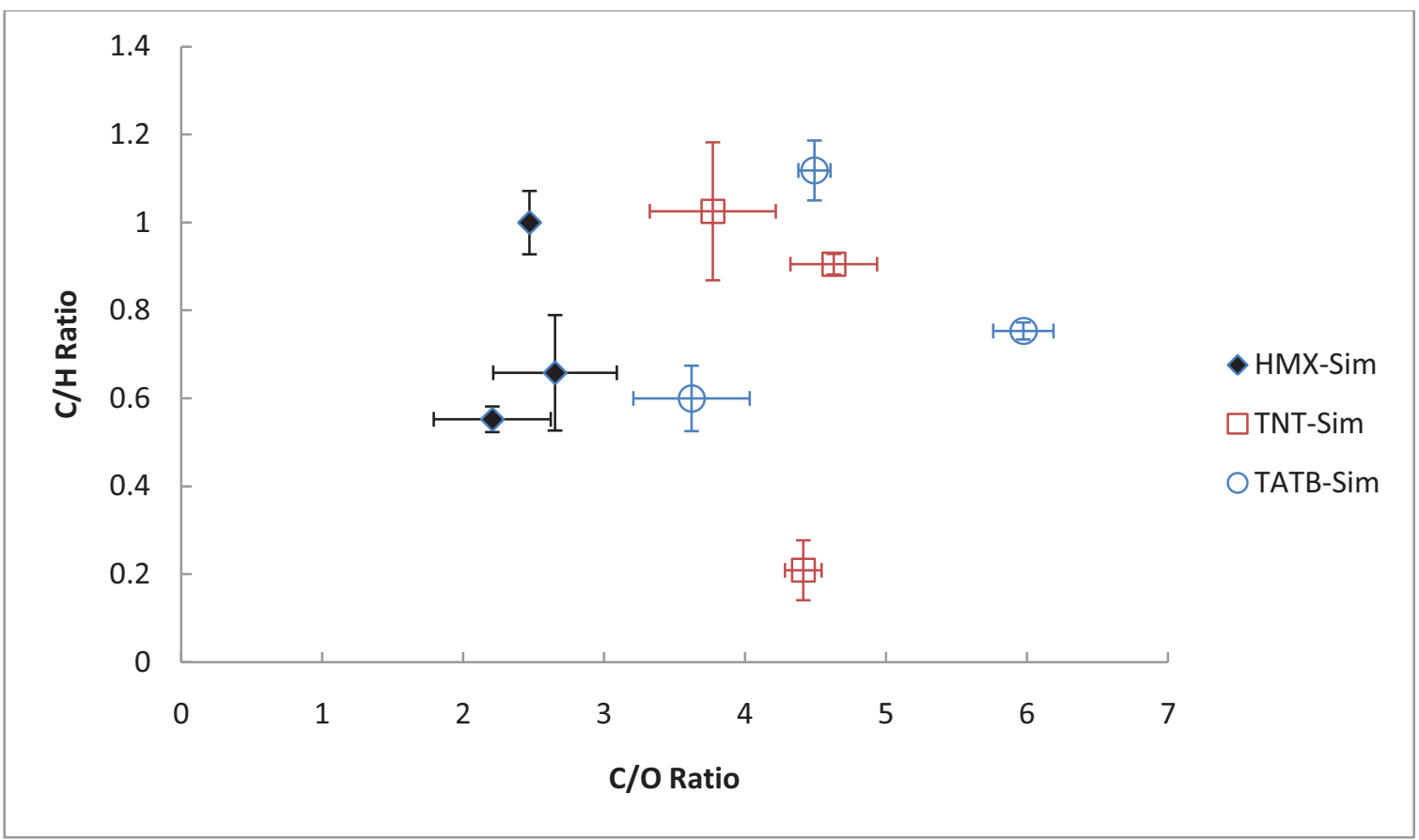

Figure 10. Carbon to hydrogen versus carbon to oxygen ratios for the three simulants.

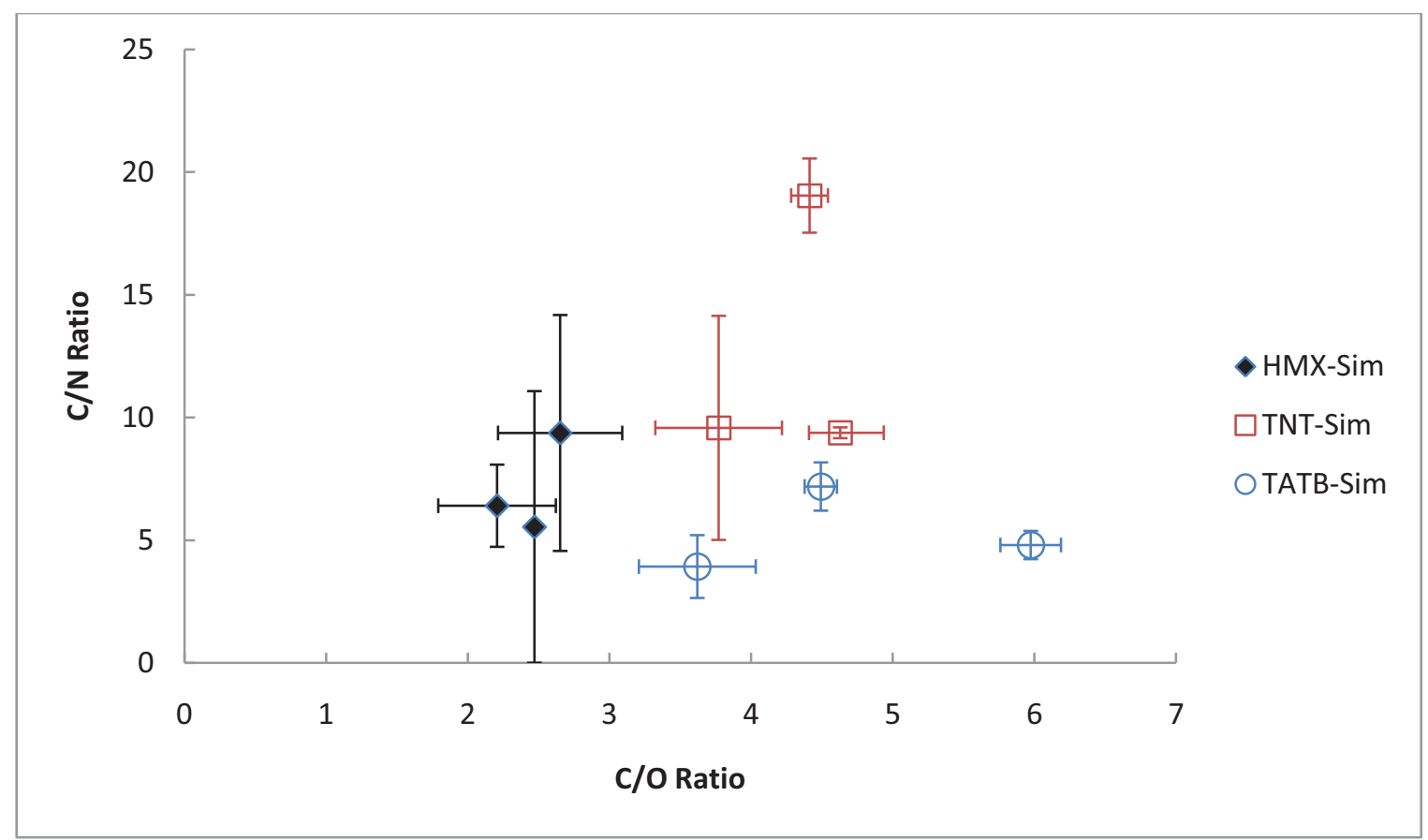

Figure 11. Carbon to nitrogen versus carbon to oxygen ratios for the three simulants. 


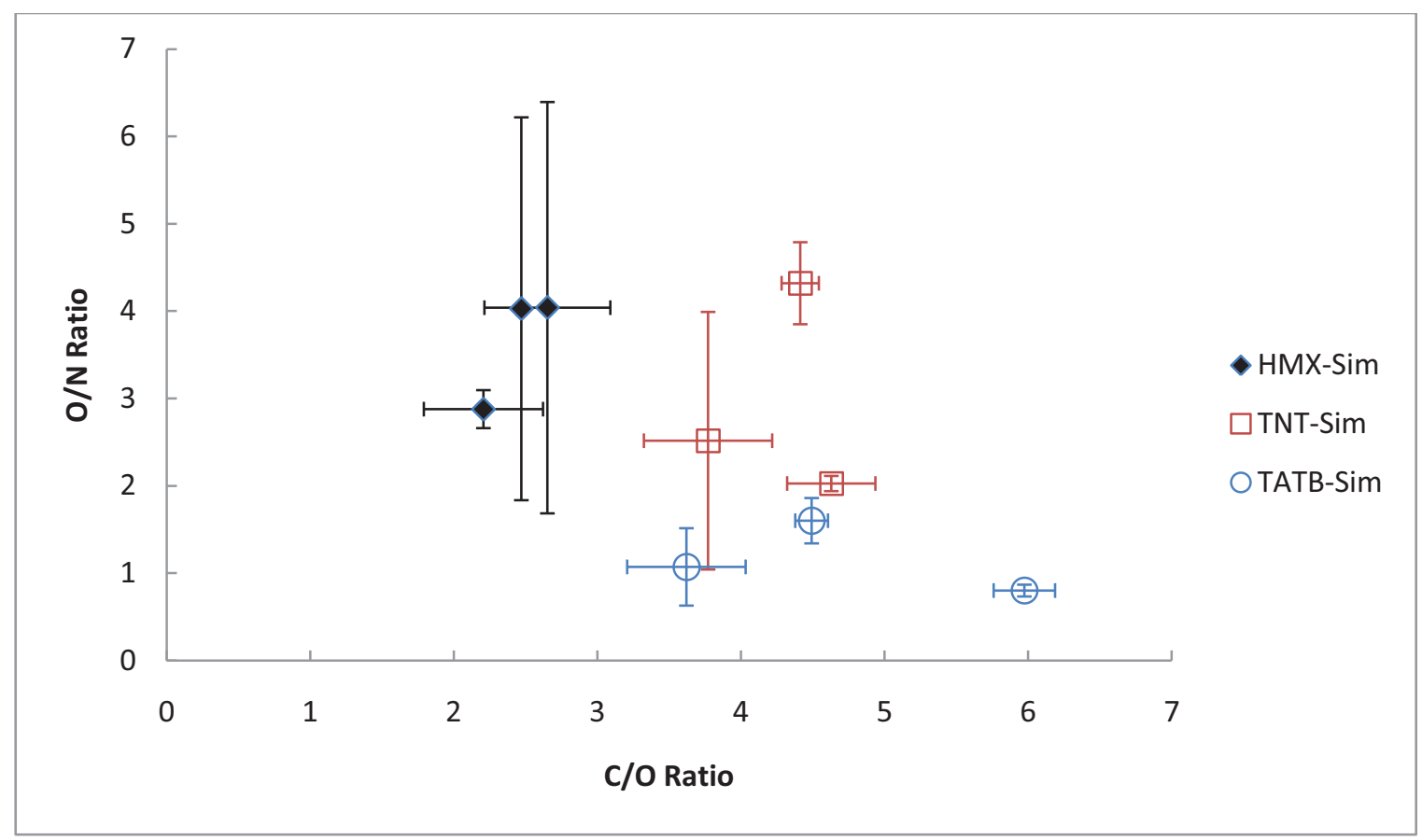

Figure 12. Oxygen to nitrogen versus carbon to oxygen ratios for the three simulants.

Figure 10 shows that the carbon to oxygen ratio discriminates the HMX simulant from the TATB and TNT simulants. This is as expected from the MCNP calculations shown in Figure 2 and the elemental ratios of the simulants themselves. The similar values of the $\mathrm{C} / \mathrm{O}$ ratio for TATB and TNT is also to be expected, based on the MCNP calculations. Similarly, the $\mathrm{C} / \mathrm{N}$ and $\mathrm{O} / \mathrm{N}$ ratios shown in Figures 11 and 12 allow one to distinguish the TNT simulant from the TATB simulant as one would expect from the known elemental ratios of their components given in Table 3.

\subsection{Results from real explosives}

The results of the elemental ratios from the real explosive measurements are shown in Table 6 below. As can be seen in the table, the C-4 measurements give results that are consistent with the HMX simulant, although we would expect the $\mathrm{C}-4$ measurement to have reduced $\mathrm{O} / \mathrm{N}$ and $\mathrm{C} / \mathrm{N}$ ratios when compared with the simulant measurement. The $\mathrm{C} / \mathrm{H}$ ratio for $\mathrm{C}-4$ is consistent with the $\mathrm{HMX}$ simulant measurements as is expected.

The Comp. B results yield a $\mathrm{C} / \mathrm{O}$ ratio that is lower than expected. It is within the range consistent with the HMX-sim results, but one would expect a ratio between that of the HMX-sim measurements and the T NT-sim measurements, on the order of 3.0. The $\mathrm{C} / \mathrm{H}$ ratio shows the expected increase when comparing $\mathrm{C}-4$ and Comp. $\mathrm{B}$, but the $\mathrm{C} / \mathrm{N}$ ratio does not.

The booster charges used show $\mathrm{C} / \mathrm{O}$ and $\mathrm{C} / \mathrm{H}$ ratios consistent with the $\mathrm{HMX}$-simulant and the $\mathrm{C}-4$ measurement. This is expected given the elemental weight ratios shown in Table 3 . The increased $\mathrm{C} / \mathrm{N}$ and $\mathrm{O} / \mathrm{N}$ ratios are also expected given that these boosters are PETN-based. 
Table 6. Elemental ratios from measurements on real explosives

\begin{tabular}{|l|l|l|l|l|}
\hline Explosive & $\mathrm{C} / \mathrm{O}$ & $\mathrm{C} / \mathrm{H}$ & $\mathrm{C} / \mathrm{N}$ & $\mathrm{O} / \mathrm{N}$ \\
\hline C-4 & $2.6 \pm 0.15$ & $2.1 \pm 1.3$ & $8.1 \pm 0.97$ & $3.1 \pm 0.35$ \\
\hline Comp. B & $2.3 \pm 0.29$ & $3.8 \pm 2.3$ & $6.2 \pm 0.94$ & $2.7 \pm 0.07$ \\
\hline boosters & $2.5 \pm 0.04$ & $1.3 \pm 0.03$ & $16 \pm 3.9$ & $6.4 \pm 1.7$ \\
\hline
\end{tabular}




\section{CONCLUSIONS AND RECOMMENDATIONS}

The PINS system has been modified both in its hardware and software to identify explosives based on the elemental ratios it observes in the item under test. Tests of the effects of SNM on these ratios showed no apparent changes in the ratios when comparing those measured with SNM and those without.

Tests of of the modified PINS system on real explosives showed the expected results when tested on C-4 and PETN-based booster charges. Tests on a Comp. B shaped charge did not yield all the expected ratios however.

Additional testing of the system is recommended, in particular to accumulate more data on the variance of the elemental ratios among different measurements of a single explosive type. These data would allow incorporation of tighter boundaries on the thresholds used by the software to identify each explosive, as well as provide a better understanding of the confidence in a particular assessment by the software of an explosive. 


\section{References}

[1] A.J. Caffrey et al., "Chemical Warfare Agent and High Explosive Identifictaion by Spectroscopy of Neutron-induced Gamma-Rays”, IEEE Transactions on Nuclear Science 39 (1992) pp 1422-1426.

[2] E.H. Seabury and A.J. Caffrey, "Explosive Detection and Identification by PGNAA", INEEL Report INEEL/EXT-04-02475 (2004).

[3] B.M. Dobratz, LLNL Explosives Handbook UCRL-52997 (1981). 